\title{
Mezunlarının Perspektifinden Eğitim Enstitüleri
}

\author{
Mustafa Şahina, Semiha Şahin ${ }^{\mathrm{b}}$
}

\section{Özet}

Anahtar Kelimeler

Bu araştırmanın amacı, 1974-1975 öğretim yılı ile 1981-1982 öğretim yılları arasında iki yıllık eğitim enstitülerinde öğrenim gören ilkokul öğretmenlerinin kendilerini yetiştiren kurumlara ilişkin görüş ve değerlendirmelerine yer vermektir. $\mathrm{Bu}$ araştırma, mevcut bir durumun olduğu şekliyle betimlendiği tarama modelindedir. Nitel araştırma yöntemiyle yapılan araştırmanın verilerinin elde edilmesinde araştırmacılar tarafından geliştirilen yarı yapılandırılmış “illkokul Öğretmeni Yetiştiren Kurumlara İlişkin Görüşme Formu" adlı form kullanılmıştır. Araştırmanın çalışma grubunu, İzmir'de yaşamakta olan eğitim enstitülerinden mezun ilkokul öğretmenleri oluşturmuştur. Araştırma sonuçlarına göre, eğitim enstitüleri mezunları mezun oldukları enstitülerdeki öğretim elemanlarını genel olarak olumlu değerlendirmişler fakat bu okulların dönemin siyasi gelişmelerinden oldukça olumsuz etkilenmiş olduğunu da ifade etmişlerdir. Okullar bina ve donanımları bakımından diğer okullara göre daha olumlu bulunmuştur. Öğrencilerinin ise gelir durumları bakımından daha alt seviyede ve genelde kırsal kesimde yaşayan ailelerin çocukları olduğu görülmüştür.

\author{
Eğitim Enstitüsü \\ İlkokul Öğretmeni \\ Türk Eğitim Tarihi
}

Makale Hakkında

Geliş Tarihi: 02.10.2019

Kabul Tarihi: 13.03.2020

Doi: 10.18026/cbayarsos.628294

\section{Education Institutions from the Perspective of Graduates}

\begin{abstract}
The purpose of this research is to provide the perceptions and evaluations of primary school teachers who studied in two-year educational institutes between the 1974-1975 and 1981-1982 academic years. This research is based on a screening model in which an existing situation is described as it is. The semistructured "Interview Form for Primary School Teacher Training Institutions" form developed by the researchers was used to obtain the data of the research conducted by qualitative research method. The study group of the research was composed of primary school teachers who graduated from educational institutes living in Izmir. According to the results, the graduates of the educational institutes generally evaluated the teaching staff in the institutes they graduated positively, but they also stated that these schools were very negatively affected by the political developments of the period. Schools were found to be more positive in terms of building and equipment compared to other schools. Students were found to have lower income levels and found to be children from rural families in general.
\end{abstract}

Keywords

Education Institute

Primary School Teacher

History of Turkish Education

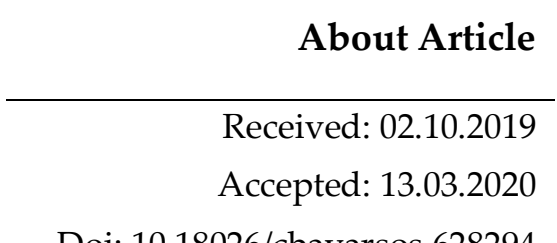

Doi: $10.18026 /$ cbayarsos.628294

\footnotetext{
a Prof. Dr., Dokuz Eylül Üniversitesi, Sosyal Bilgiler Eğitimi ABD. https://orcid.org/0000-0001-8789-514X

b Doç. Dr., Dokuz Eylül Üniversitesi, Eğitim Yönetimi ABD. https://orcid.org/0000-0002-1135-0327
} 


\section{Giriș}

Öğretmenlik, çok genel anlamıyla mesleklerin mesleği olarak tanımlanır ve toplumun sosyal, siyasal, iktisadi ve kültürel kalkınmasının kaynağı olarak görülür. Öğretmenliğe ilişkin farklı tanımlamalar da mevcuttur: Akyüz'e (1978) göre, “örgün eğitimde bir öğretim görevi ile yükümlü her derecedeki öğreticileri kapsamaktadır". Varış (1985) öğretmeni "devletin eğitim politikasını uygulamaya koyan, uygulama sonuçlarıyla politikaları etkileyen, uzmanlık çalışmaları ve araştırmalardan yararlanan, aynı zamanda bu çalışmalarla iç içe olup onlara katkı sağlayan önemli bir kişi" olarak görmektedir. Büyükkaragöz'ün (1998) tanımında ise, "öğretmen bir milletin ruh ve karakter hamuruna şekil veren üretici bir insandir".

Eğitimin niteliği öğretmenin niteliği ile ilişkilendirildiği için öğretmenliğe öteden beri çok önem verilmiştir. Eğitimdeki başarı, eğitim sistemini işleticisi öğretmenlerin niteliğiyle ilişkilendirilmiş ve insan gücünü nitelikli duruma getirmenin en stratejik öğesi olarak kabul edilmiştir. Öğretmenliğin, öğrencilerin gelişimine etki eden pek çok faktörü düzenleme, vasıflı iş gücü oluşturma, adil, değer ve kültür normları gelişmiş bireyler yetiştirme ve toplumların kalkınma sorunlarını çözme gibi sorumlulukları bulunduğu vurgusu yapılmıştır (Erdem, 2015: 18).

Eğitim sistemlerinin dönüşümü ve gelişiminde öğretmen yetiştirme politikaları önemli yer tutmaktadır. Söz konusu çabaların ardında öğretmen yetiştirme politika ve uygulamalarına yönelik eleştirilerin olduğu görülmektedir. Türk eğitim tarihi incelendiğinde, eğitimde yenileşme uğraşıları çerçevesinde öğretmen yetiştirme konusu da ele alınmış ve rüşdiyelere öğretmen yetiştirmek için, 1848 ' de başkent İstanbul'da Darülmuallimin adıyla ilk defa bir öğretmen okulu açılmıştır. Türk tarihinde ilkokul yetiştirme süreci 150 yıldır devam etmektedir. İlkokul yetiştiren ilk kurum Osmanlı'nın son evrelerinde 1868'de açlan Darülmuallimini Sıbyan'dır. Darülmuallimin'in adı 1924'de muallim mektepleri, 1935'de öğretmen okulları olarak değiştirilmiştir. 1940'da köye yönelik öğretmen yetiştirme politikasının bir gereği olarak açılan köy enstitüleri nedeniyle 1954'e kadar ilkokul öğretmeni iki ayrı kanaldan yetişmiştir. 1954' de söz konusu kurumlar ilköğretmen okulları adı altında birleştirilmiştir. 1970-1971 öğretim yılına kadar ilkokul öğretmenleri ilkokul üzerine altı yıl ve ortaokulun üzerine üç yıllık düzeylerde yetiştirilmiştir. Aynı yıl ilköğretmen okullarının öğrenim düzeyi ilkokul üzerine yedi yıl ve ortaokulların üzerine dört yıl olarak biçimlendirilmiştir. O yıl itibariyle, 28 adedi yedi yıllık, 61 adedi ise dört yıllık olmak üzere ilköğretmen okullarının toplam sayısı 89'dur. 1974-1975 öğretim yılında ilkokul yetiştirmenin süresi uzatılarak lisenin üzerine iki yıl eğitim veren eğitim enstitüleri açılmıştır. Böylelikle 50 yıl süren lise düzeyinde eğitim veren ilkokul öğretmeni yetiştiren kurumlar sona ermiştir. 89 ilköğretmen okulundan önemli bölümü iki yıllık eğitim enstitüsüne dönüşürken bir bölümü öğretmen lisesi olarak eğitim vermeye devam etmiştir. Bu okulların sayıları 1981'de 17'ye indirilmiş, 1982'de ise eğitim yüksekokuluna dönüştürülüp üniversiter bir kimliğe büründürülmüştür. Bu okulların öğretim süresi 19891990 öğretim yılında 4 yıla çıkarılmış ve 1992'de eğitim fakültelerine dönüştürülmüştür (Akyüz, 2012: 380-383; Ataünal, 1994: 48-51; Dilaver, 1994: 30-37; Dursunoğlu, 2003; Eşme, 2001; Küçükoğlu, 2004: 1-15, Şahin, 2011: 1119-1133; Ünal ve Birbudak, 2013: 65-104).

Araştırmanın Amacı: Bu araştırmanın amacı, 1974-1975 öğretim yılı ile 1981-1982 öğretim yılları arasında iki yıllık eğitim enstitülerinde öğrenim gören ilkokul öğretmenlerinin kendilerini yetiştiren kurumlara ilişkin görüş ve değerlendirmelerine yer vermektir. Araştırmanın problem cümlesi "eğitim enstitülerinden mezun olan öğretmenler mezun 
oldukları enstitüleri bazı değişkenler açısından nasıl değerlendirmektedirler?" şeklinde dizayn edilmiştir. Bu çerçevede araştırmanın alt problemleri şöyle oluşturulmuştur: Eğitim enstitülerinden mezun olan öğretmenler mezun oldukları enstitüleri, a) öğretmenleri ve derslerin etkililiği, b) öğrenci profili/özellikleri, c) fiziksel mekân/ özellikler ve araç-gereçleri, d) ortamı (felsefesi, yönetimi ve yönetsel süreçleri vb.), e) mezunlarının mesleki yeterlilikleri açısından nasıl değerlendirmektedirler?

\section{Yöntem}

Araştırmanın Deseni: Bu araştırma, mevcut bir durumun olduğu şekliyle betimlendiği tarama modelindedir. Nitel araştırma yöntemiyle yapılan araştırmanın verilerinin elde edilmesinde araştırmacılar tarafından geliştirilen yarı yapılandırılmış "İlkokul Öğretmeni Yetiştiren Kurumlara İlişkin Görüşme Formu" adlı form kullanılmıştır.

Çalışma Grubu: Araştırmanın çalışma grubunu, İzmir'de yaşamakta olan eğitim enstitülerinden mezun ilkokul öğretmenleri oluşturmuştur. Amaçlı örneklem yöntemlerinden kolay ulaşılabilir örneklem yöntemiyle 16 öğretmen çalışma grubunda yer almaktadir.

Veri Toplama Aracı: Nitel araştırma yöntemiyle yapılan araştırmanın verilerinin elde edilmesinde; açık uçlu yarı yapılandırılmış "İlkokul Öğretmeni Yetiştiren Kurumlara İlişkin Görüşme Formu" kullanılmıştır. Ölçme aracının öğretmenlerin öğretmen yetiştiren kurumlara ilişkin algılarını ne derecede temsil ettiği uzman görüşüne başvurularak belirlenmiş olup kapsam ve görünüş geçerliliğine de bakılmıştır. Formdaki sorulardan

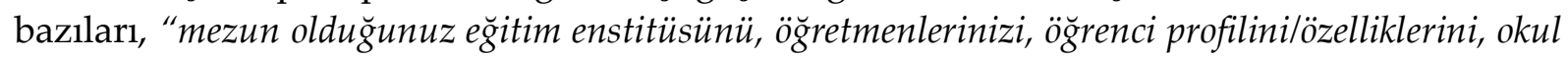
ortamını nasıl değerlendirirsiniz?" şeklinde sıralanabilir. Veriler bu formdaki sorulara verilen cevaplardan elde edilmiştir.

Verilerin Analizi: Araştırmadan elde edilen veriler içerik analizi yapılarak iki uzman tarafından kodlanmış ve temalar oluşturulmuştur (Miles \& Huberman 1994; Yıldırım \& Şimşek, 2008). Araştırmanın verileri, sistematize edilerek bilgisayar ortamına aktarılmış; nitel araştırmada kullanılan veri kodlama, azaltma, veri sunma ve veri doğrulama yaklaşımıyla analiz edilmiştir. Kodlamalar sonucu ölçeğin madde uyuşum yüzdesi .87 bulunmuştur (Miles \& Huberman 1994).

\section{Bulgular}

Araştırmanın ilk alt problemi olan "öğretmenler mezun oldukları eğitim enstitülerinin öğretmenlerini ve derslerin etkililiğini nasıl değerlendirmektedirler" sorusuna aranan cevap tablo 1 'de sunulmuştur.

Tablo 1. Eğitim Enstitülerinde Görev Yapan Öğretmenlere Yönelik Değerlendirme

\begin{tabular}{lcccc}
\hline & \multicolumn{2}{c}{ Öğretmen Sayısı } & \multicolumn{2}{c}{ Dile Getirilme Sıklığı } \\
Eğitim Enstitüsü Öğretmenleri & $\mathbf{f}$ & $\mathbf{\%}$ & $\mathbf{f}$ & $\mathbf{\%}$ \\
\hline Derse hazırlıklı geliyorlardı. & 10 & 63 & 10 & 63 \\
Öğrenciye karşı tutumları olumluydu. & 10 & 63 & 10 & 53 \\
Alan bilgisi bakımından donanımlıydılar. & 8 & 50 & 8 & 25 \\
İyi eğitim verdiler. & 4 & 25 & 4 & 13 \\
Enstitüdeki öğretmen sayısı yeterliydi. & 4 & 25 & 2 & 25 \\
Enstitüdeki öğretmen sayısı yetersizdi. & 4 & 25 & 4 & 13
\end{tabular}




\begin{tabular}{lllll} 
Lise öğretmenleri derse girmekteydi. & 2 & 13 & 2 & 13 \\
Derse hazırlıklı gelmiyorlardı. & 2 & 13 & 2 & 13 \\
\hline
\end{tabular}

Tablo 1'e göre katılımcıların \%63'ü mezun oldukları eğitim enstitülerindeki öğretmenlerinin derse hazırlıklı geldiklerini, öğrencilere karşı tutumlarının olumlu olduğunu, \%50'si ise öğretmenlerinin alan bilgilerinin tatmin edici düzeyde olduğunu belirtmiştir. Katılımcıların sadece \%13'ü öğretmenlerinin yetersizliğine değinmiştir.

Katılımcıların konuyla ilgili ifadeleri şöyledir: "Dersler etkiliydi ve meslek hayatında işe yarayacak bilgiler verildi. Bazı hocalarımı bilgi bakımından yeterliydi, bazı hocalarımı ise son derece yetersizdi". "Hocaların derslere hazırlıklı geldiklerini düşünmüyorum. Derslerimize çoğunlukla lise öğretmenleri geliyordu. Hocaların bazlları bizlere lise öğrencisi gibi davranıyordu. Zaman zaman biz de kendimizi lise de hissediyorduk. Enstitüde de zaten sadece bir tane asistan vardi. 80 darbesi sonrası öğrenciye baskı vardl. Derse hazırlıkl gelmiyorlardı. Siyasi çalkantılar sonrası eğitimin kalitesi bozulmaya başladı. Tam bir eğitim öğretim yapılamadı. Öğrenciye karşı siyasi yaklaşımlar sergilendi." Araştırmanın ikinci alt problemi olan "öğretmenler mezun oldukları eğitim enstitülerini öğrenci profili/özellikleri açısından nasıl değerlendirmektedirler" sorusuna aranan cevap tablo 2'de sunulmuştur.

Tablo 2: Eğitim Enstitülerinin Öğrenim Gören Öğgrencilerin Profilleri/Özellikleri

\begin{tabular}{|c|c|c|c|c|}
\hline \multirow[t]{2}{*}{ Öğrenci Profili/Özellikleri } & \multicolumn{2}{|c|}{$\begin{array}{l}\text { Öğretmen } \\
\text { Sayısı }\end{array}$} & \multicolumn{2}{|c|}{$\begin{array}{l}\text { Dile Getirilme } \\
\text { Siklığ }\end{array}$} \\
\hline & f & $\%$ & $\mathbf{f}$ & $\%$ \\
\hline $\begin{array}{l}\text { Öğgrenciler kısa yoldan meslek sahibi olmak için eğitim enstitüsünü } \\
\text { tercih etmişlerdi. }\end{array}$ & 10 & 63 & 10 & 63 \\
\hline $\begin{array}{l}\text { Öğrenciler daha çok Doğu kökenli ve alt gelir grubuna sahip ailelerin } \\
\text { çocuklarıdıllar. }\end{array}$ & 6 & 38 & 6 & 38 \\
\hline $\begin{array}{l}\text { Siyasetin okula girmesiyle birlikte okulda sıkıntılar başladı ve öğrenci } \\
\text { profili değişti. }\end{array}$ & 6 & 38 & 6 & 38 \\
\hline Öğretmen okulu mezunları daha başarılıydılar. & 6 & 38 & 6 & 38 \\
\hline Öğrenciler yeterli birikime sahip değildi. & 4 & 25 & 4 & 25 \\
\hline Öğrenciler dönemin şartlarına göre iyiydi. & 2 & 13 & 2 & 13 \\
\hline Hızlandırılmış eğitimle birlikte kalite bozuldu. & 2 & 13 & 2 & 13 \\
\hline
\end{tabular}

Tablo 2'ye göre katılımcıların \%63'ü eğitim enstitülerine gelen öğrencilerinin birinci amacının öğretmen olmak değil, kısa yoldan bir meslek sahibi olmak olduğunu belirtmişlerdir. Öğretmenlerin \%38'i bu okullardaki öğrencilerin alt ekonomik gelir grubundan ve daha çok Doğu kökenli olduğunu; öğretmen okulu mezunu olanların öğretmenlik mesleğine uygun davrandıklarını ve siyaset nedeniyle öğrenci profilinin değiştiği görüşünü paylaşmışlardır.

Bazı katılımcıların konuya ilişkin ifadeleri şöyledir: "Meslek sahibi olmak için eğitim enstitüsüne gelmişlerdi. Birinci tercihleri öğretmen olmak değildi. Öğretmenliğe karşı olumsuz tutumlar sergiliyorlardı. Her yerden öğrenci vardı ama öğretmen liselerinden gelenler daha başarılıydılar. Onlar öğretmenliğe hazırlanıp gelmişlerdi. Çok farklı profile sahip öğrenciler vardı. Fakat öğretmen olabilecek yeterlilikte öğretmen adayı yoktu. Birikimli öğrenciler yoktu. Öğrenciler kendi içine kapanı, düşüncelerini ifade etmekten çekinen öğrencilerdi. Birçoğu Doğu kökenli, alt gelir grubuna 
dâhil ailelerin çocuklarıydı. Siyasetin okula girmesiyle birlikte okulda ciddi sıkıntılar yaşanmaya başlandı ve öğrenci profilleri değişti. Sanki ilkokul mezunları bile okula alınmışlardı.

Araştırmanın üçüncü alt problemi olan "öğretmenler mezun oldukları eğitim enstitülerini fiziksel mekân ve araç-gereç özelliklerinin yeterlilikleri bakımından nasıl değerlendirmektedirler" sorusuna aranan cevap tablo 3'de sunulmuştur.

Tablo 3: Eğitim Enstitülerinin Fiziksel Mekân/Özellikleri

\begin{tabular}{|c|c|c|c|c|}
\hline \multirow[t]{2}{*}{ Fiziksel Mekân ve Araç-Gereç Özellikleri (Yeterliliği) } & \multicolumn{2}{|c|}{$\begin{array}{l}\text { Öğretmen } \\
\text { Sayısı }\end{array}$} & \multicolumn{2}{|c|}{$\begin{array}{l}\text { Dile Getirilme } \\
\text { Sıklığı }\end{array}$} \\
\hline & $\mathbf{f}$ & $\%$ & $\mathbf{f}$ & $\%$ \\
\hline $\begin{array}{l}\text { Öğretmen okulundan devralındığından okulun fiziki mekânı ve teknik } \\
\text { donanımı iyiydi. }\end{array}$ & 12 & 75 & 12 & 75 \\
\hline $\begin{array}{l}\text { Fiziksel mekân ve teknik donanım yeterli değildi, ihtiyaçlara cevap } \\
\text { vermiyordu. }\end{array}$ & 8 & 50 & 8 & 50 \\
\hline $\begin{array}{l}\text { Spor salonu, kütüphane, yemekhane, kantin ve laboratuvarlar tam } \\
\text { donanimliydı. }\end{array}$ & 6 & 38 & 6 & 38 \\
\hline Okulda iş teknik odası ve müzik odaları bulunmaktaydı. & 6 & 38 & 6 & 38 \\
\hline $\begin{array}{l}\text { Haftada bir gün film gösterimi yapılırdı ve tarım dersleri için alan } \\
\text { mevcuttu. }\end{array}$ & 6 & 38 & 6 & 38 \\
\hline Sadece spor salonu mevcuttu. & 2 & 13 & 2 & 13 \\
\hline $\begin{array}{l}\text { Kitaplara ulaşmak zordu, kaynak sıkıntısı yaşanıyordu, yemekler } \\
\text { yetersizdi. }\end{array}$ & 2 & 13 & 2 & 13 \\
\hline
\end{tabular}

Tablo 3'e göre katılımcıların \%75'i enstitü binalarının önceden öğretmen okulu binası olduğu için fiziksel yapısının ve teknik donanımının yeterli olduğunu ifade etmişlerdir. Yine tablodan anlaşılacağı üzere birçok okulda kütüphane ve spor salonlarının mevcut olduğu görülmektedir. Katılımcıların \%50'si bu okulların teknik donanımının ihtiyaçlara cevap verecek nitelikte olmadığını vurgulamışlardır.

Katılımcılardan bazıları genel olarak olumlu ifadeler kullanmışken bazıları da olumsuz yargılarda bulunmuşlardır: “Öğretmen okulundan eğitim enstitüsüne dönüştüğü için donanım daha iyiydi. Spor salonu, kütüphane, yemekhane ve kantin mevcuttu. Laboratuvarlar genel olarak donanımlıydı". "Enstitümüz fiziksel mekân bakımından hiç yeterli değildi, ihtiyaçlara cevap vermiyordu, kitaplara ulaşmak zordu. Enstitümüzde kaynak sıkıntısı yaşandığını gözlüyorduk bu nedenle yemekler bile hem kalite hem de miktar olarak yetersizdi".

Araştırmanın dördüncü alt problemi olan "öğretmenler mezun oldukları eğitim enstitülerini okul ortamı bakımından nasıl değerlendirmektedirler" sorusuna aranan cevap tablo 4'de sunulmuştur.

Tablo 4: Eğitim Enstitülerinin Okul Ortamı Açısından Değerlendirilmesi

\begin{tabular}{lcccc}
\hline Okul Ortamı & \multicolumn{2}{c}{ Öğretmen } & \multicolumn{2}{c}{ Dile Getirilme } \\
& Sayısı & \multicolumn{2}{c}{ Sıklığ } \\
& f & fo & f & \% \\
\hline $\begin{array}{l}\text { Baskıcı bir eğitim sistemi vardı, dönemin siyasi koşulları eğitim üzerinde } \\
\text { etkiliydi. }\end{array}$ & 10 & 63 & 12 & 75 \\
$\begin{array}{l}\text { Öğrencilerin kendi çabalarıla sosyal, sanatsal ve sportif etkinlikler } \\
\text { yapılmaktaydı. }\end{array}$ & 8 & 50 & 6 & 38
\end{tabular}


Öğretmen-öğrenci, öğrenci-öğrenci ilişkileri iyiydi.

$\begin{array}{llll}4 & 25 & 4 & 25 \\ 4 & 25 & 4 & 25 \\ 4 & 25 & 4 & 25 \\ 4 & 25 & 4 & 25 \\ 2 & 13 & 2 & 19\end{array}$

Tablo 4'e göre katılımcıların \%63'ü eğitim enstitülerinde baskıcı bir eğitimin olduğunu ve dönemin siyasi koşullarının eğitim üzerinde etkili olduğunu ifade etmişlerdir. Kendi çabalarıyla sosyal, sanatsal ve sportif etkinlik yapmanın mümkün olduğunu ifade edenlerin oran1 $\% 50$ 'dir.

Bazı katılımcıların konuya ilişkin ifadeleri şöyledir: "Siyasi çalkantılar sonrası eğitimin kalitesi bozulmaya başladı. Tam bir eğitim öğretim yapılamadı. Öğrenciye karşı siyasi yaklaşımlar sergilendi. Öğretmenlerimizle bizlerin yaş aralığı fazla olmadı ̆̆ı için să̆lıklı ilişkiler kurulabiliyordu". "Baskıcı bir eğitim sistemi vardı. Siyasi çekişmeler kurum yapısını değiştirdi. Siyasi çalkantılarla birlikte öğrenci profilinde değişiklikler yaşanmaya başlandı. İlkokul mezunları bile okula alındılar. Hızlandırılmış eğitimle 40 günde öğretmen olanlar vardı. Olağanüstü dönemin şartları, sistemin içinde baskın şekilde hissedilmekteydi. Okulda baskı vardı. Sürekli olarak okulun içinde yatakhanelere baskınlar yapılırdı. Baskıcı bir sistem vardı. Dönemin siyasi koşulları eğitim üzerinde etkiliydi. Öğretmen öğrenci ilişkisi yoktu. Öğrenciler okula gitmeye korkardı. Haftada bir gün film gösterimleri gerçekleştirildi. Tarım dersleri için uygulama alanları mevcuttu. Öğrenciler okula gitmeye korkardı. Önceden sosyal faaliyetler olmasına rağmen sonradan hepsi kaldırıldı."

Araştırmanın beşinci alt problemi olan "öğretmenler mezun oldukları eğitim enstitülerini meslekteki yeterlilik bakımından nasıl değerlendirmektedirler" sorusuna aranan cevap tablo 5'de sunulmuştur.

Tablo 5: Eğitim Enstitüleri Mezunlarının Meslekteki Yeterlilikleri

\begin{tabular}{lcccc}
\hline Mesleki Yeterlilik & \multicolumn{2}{c}{ Öğretmen } & \multicolumn{2}{c}{ Dile Getirilme } \\
& \multicolumn{2}{c}{ Sayısı } & \multicolumn{2}{c}{ Sıklığ } \\
& $\mathbf{f}$ & $\%$ & $\mathbf{f}$ & \% \\
\hline Öğretmen okulu mezunları daha başarılı. & 10 & 63 & 14 & 88 \\
Öğretmenlik mesleğin içinde öğrenildi. & 6 & 38 & 10 & 63 \\
Sonraki kurumlardan mezun olanlardan daha başarılıydılar. & 2 & 13 & 4 & 25 \\
Başarılı olanların yanında başarısız olanlar da vardı. & 2 & 13 & 2 & 13 \\
40 günde öğretmen olanlardan başarı beklenemezdi. & 2 & 13 & 2 & 13 \\
\hline
\end{tabular}

Tablo 5'e göre katılımcıların \%63'ü öğretmen okulu mezunlarını daha başarılı bulduklarını belirtmişlerdir. Katılımcıların \%38'i öğretmenliği mesleği yaparken öğrendiklerini ifade etmişlerdir. Bazı katılımcıların konuya ilişkin ifadeleri şöyledir: “Öğretmen okulu mezunları daha iyiydiler çünkü öğretmen okullarında işin mutfağında yetişiyorlardı. Onlar yaparak yaşayarak eğitim aldıklar için mesleklerinde daha başarllıydılar. Onlara yönelik olumsuz değerlendirilebilecek hiçbir özellik yoktur. Disipline dayalı ve gelenekçi eğitim sistemi uygulamaları eleştiri konusu yapılabilir. Hızlandırılmış eğitimle 40 günde öğretmen olanlar vardı. Bu öğretmenlerin görevde başarılı olacaklarına inanmıyorum". 


\section{Sonuç}

Araştırma sonucuna göre, eğitim enstitüleri mezunları mezun oldukları enstitülerdeki öğretim elemanlarını genel olarak olumlu değerlendirmekte, derslere hazırlıklı geldiklerini ve öğrencilere karşı tutumlarının olumlu olduğunu belirtmektedirler. Genel olarak enstitü öğretmenleri hakkında olumlu bir çerçeve çizilmesi, söz konusu eğitim enstitülerinde görev yapan öğretim elemanlarının çoğunlukla köy enstitüleri veya ilköğretmen okulu mezunu olmalarına bağlanabilir.

Öğrenci profillerine bakıldığında eğitim enstitülerinde okuyan öğrencilerin gelir durumları bakımından daha alt seviyede ve genelde kırsal kesimde yaşayan ailelerin çocukları olduğu görülmüştür. Bu durum ekonomik durumu iyi olan ailelerin çocuklarının daha fazla gelir getirecek mesleklere yöneldiklerini gelir durumu az olan ailelerin ise çocuklarını öğretmenliğe yönelttiklerini ve eğitim enstitülerine gönderdiklerini düşündürtmektedir.

Araştırmanın diğer önemli bir sonucu ise eğitim enstitülerinin teknik donanımlarıyla ilgilidir. Eğitim enstitülerinin bina ve donanımları köy enstitüsü ve ilköğretmen okullarından kaldığı için genellikle yeterli görülmüştür. Öğretmen okulları, köy enstitülerinin felsefesini uzun zaman sürdürmüş ve bazı öğretmen okullarının eğitimi aynı binalarda devam etmiştir. Kısaca 1940'lardan itibaren yapılan bu okul binaları ve teknik donanımı öğretmenler tarafından diğer okullara göre daha olumlu değerlendirilmiştir.

Araştırmadan çıkan önemli sonuçlardan biri de bu okulların dönemin siyasi gelişmelerinden oldukça olumsuz etkilenmiş olması ve buna bağlı olarak eğitim enstitülerinin baskıcı bir anlayışla yönetilmeye çalışılmasıdır. Bu araştırmaya göre, eğitim enstitülerinde yönetim süreçleri/ortamı sekteye uğramış ve dersler aksayabilmiştir. Gelen öğrenci profili iktidara göre değişmiş, öğretim süresi kısaltılmış (40 günde bile öğretmen yetiştirilmiş) ya da dersler yapılamamıştır. Bu durum söz konusu eğitim kurumlarının 1980'e kadar geçen süreçte ülkenin siyasi karmaşasına koşut olarak açıklanabilir. O dönemlerde eğitim enstitülerinde görev yapan öğretim elemanlarının ve yöneticilerin doğrudan veya dolaylı olarak o sürece katıldıkları bilinmektedir. Her koşulda durumun getirdiği ortamdan veya yanlı tutumlardan dolayı öğrenciler bu baskı ortamından etkilenmiş olabilirler (Akyüz, 2012; Baykan, 2004, 286287; Kaya, 1984; Sağlam, 2007: 351; Şahin, 2012).

Araştırmanın bir diğer sonucuna göre, eğitim enstitülerinden mezun öğretmenler mesleki yeterliliklerini öğretmenlik yaparken yıllar içinde geliştirmiştir. Aynı mezunlar öğretmen okulu mezunu olanları bu konuda daha başarılı bulmuşlardır. Eğitimin dinamik bir yapı olması gelişen, değişen sistemlere ayak uydurma zorunluluğunda olmasıyla açıklanabilir.

\section{Kaynakça}

Akyüz, Y. (1978). Türkiye'de öğretmenlerin toplumsal değişmeye etkileri. Ankara: Doğan Basımevi.

Akyüz, Y. (2012). Türk eğitim tarihi. Ankara: PegemA Akademi.

Ataünal, A. (1994). Türkiye'de ilkokul öğretmeni yetiştirme sorunu (1923-1994). Ankara: Milli Eğitim Bakanlığı Yayınları.

Baykan, D. (2004). Nĭğde öğretmen okulları. (Yüksek Lisans Tezi, Niğde Üniversitesi, Niğde). Erişim adresi: https://tez.yok.gov.tr/UlusalTezMerkezi/tezSorguSonucYeni.jsp

Büyükkaragöz, S. (1998). Öğretmenlik mesleğine giriş. Konya: Mikro Yayınları. 
Dilaver, H. H. (1994). Türkiye'de öğretmen yetiştirme ve istihdam şartları. İstanbul: Milli Eğitim Bakanlığı Yayınları.

Dursunoğlu, H. (2003). Cumhuriyet döneminde ilköğretime öğretmen yetiştirmenin tarihi gelişimi, Erişim Adresi: https://dhgm.meb.gov.tr/yayimlar/dergiler/Milli Egitim Dergisi/160/dursunoglu.htm

Erdem, A. R. (2015). Türkiye'deki öğretmen yetiştirmenin A, B, C'si. Journal of Teacher Education and Educators, 4 (1), 16-38.

Eşme, İ. (2001). Yüksek öğretmen okulları. İstanbul: Bilgi-Başarı Yayınevi.

Kaya, Y. K. (2015). Insan yetiştirme düzenimiz. Ankara: PegemA Yayıncılık.

Küçükoğlu, A. (2004). Türkiye'nin öğretmen yetiştirme serüveninde eğitim enstitüleri ve bir model olarak Kâzım Karabekir Eğitim Enstitüsü. XIII. Ulusal Eğitim Bilimleri Kurultayı bildirileri içinde. Malatya: İnönü Üniversitesi Eğitim Fakültesi Yayını.

Miles, M. B. \& Huberman, A. M. (1994). Qualitative data analysis: An expanded sourcebook. Thousand Oaks: Sage.

Sağlam, A. (2007). Gaziantep öğretmen okulları. (Yüksek Lisans Tezi, Niğde Üniversitesi, Niğde). Erişim adresi: https://tez.yok.gov.tr/UlusalTezMerkezi/tezSorguSonucYeni.jsp

Şahin, M. (2011). Öğretmen yetiştirmede Buca Eğitim Fakültesi uygulaması (1959-2009)". Cemil Öztürk \& İlhami Fındıkçı (Ed.), Prof. Dr. Yahya Akyüz'e armağan kitabı içinde (ss. 1119-1133). İstanbul: Pegem Akademi.

Ünal, U. \& Birbudak, T. S. (2013). İstanbul darülmuallimini (1848-1924). Ankara: Atatürk Araştırma Merkezi Yayını.

Varış, F. (1985). Eğitim bilimine giriş. Ankara: Ankara Üniversitesi Eğitim Bilimleri Fakültesi Yayini.

\section{Görüşme Formu}

"Mezunlarının Perspektifinden Eğitim Enstitüleri" başlıklı araştırma için eğitim enstitülerinden mezun olmuş öğretmenlerle yapılan görüşmelerde kullanılan yarı yapılandırılmış görüşme formunun soruları şunlardır:

1) Öğrenim gördügünüz eğitim enstitülerinin öğretmenleri ve derslerin etkililiği sizce nasildı?

2) Öğrenim gördüğünüz eğitim enstitülerinin öğrenci profili ve özellikleri sizce nasıldı?

3) Öğrenim gördüğünüz eğitim enstitülerinin fiziksel mekânları, araç-gereçleri yeterli miydi?

4) Öğrenim gördügünüz eğitim enstitülerinin okul ortamı nasıldı?

5) Öğrenim gördügünüz eğitim enstitüleri mezunlarını mesleki yeterlilikleri nasıldı? 